\title{
Methane measurements from space: technical challenges and solutions
}

Haris Riris $^{* a}$, Kenji Numata ${ }^{\mathrm{a}}$, Stewart Wu ${ }^{\mathrm{a}}$, Brayler Gonzalez ${ }^{\mathrm{a}}$,

Michael Rodriguez ${ }^{b}$, Stephan Kawa ${ }^{a}$, Jianping $\mathrm{Mao}^{\mathrm{c}}$

a NASA Goddard Space Flight Center, Greenbelt, MD 20771

b Sigma Space Corporation, Lahnam, MD 20706

c Earth System Science Interdisciplinary Center (ESSIC), University of Maryland, College Park, MD 20740 


\section{Outline}

- 1. Motivation

-Why measure Methane?

- 2. Measurement Approach

- Technology and Challenges

- 3. 2015 Airborne Demonstration

- OPA

$-\mathrm{OPO}$

- 4. Summary 


\section{Motivation}

- Why measure methane?

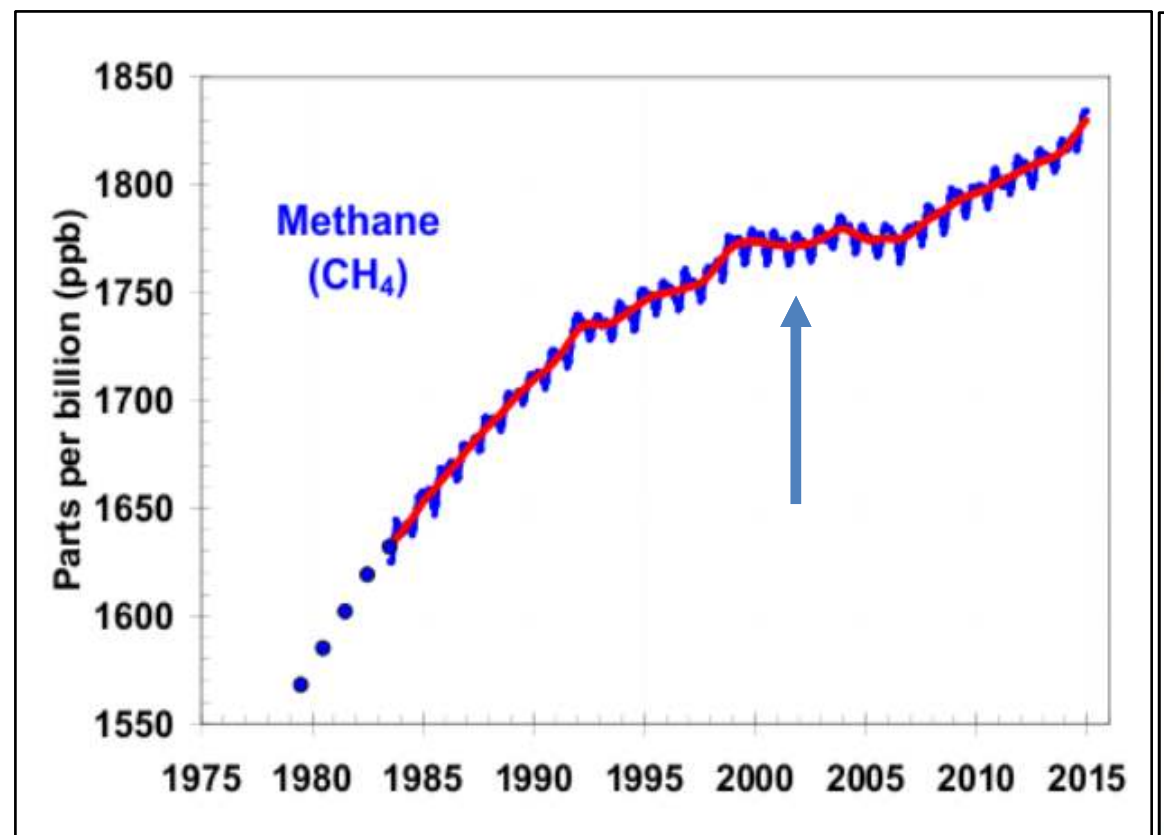

Source: www.esrl.noaa.gov/gmd/aggi/aggi.html

Methane Trend since 1975

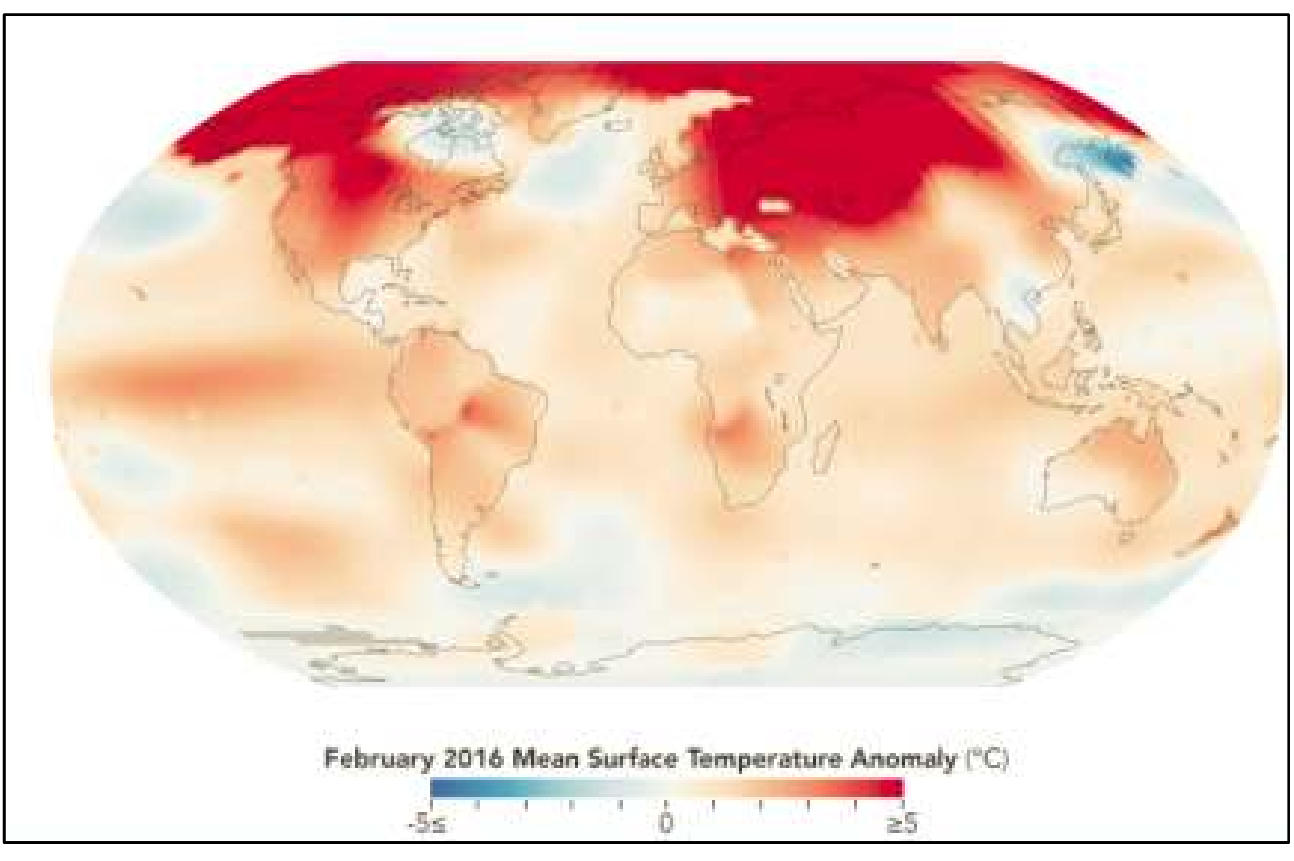

Source: http://www.giss.nasa.gov/research/features/201603_gistemp/

February 2016 was the warmest February in 136 years of modern temperature records. That month deviated more from normal than any month on record. 


\section{Methane Lifetime}

\begin{tabular}{|c|c|c|c|c|c|}
\hline Gas & $\begin{array}{l}\text { Estimated } 1750 \\
\text { tropospheric } \\
\text { concentration } 1\end{array}$ & $\begin{array}{l}\text { Recent } \\
\text { tropospheric } \\
\text { concentration }^{2}\end{array}$ & $\begin{array}{l}\text { GWP }^{3}(100-y r \\
\text { time horizon) }\end{array}$ & $\begin{array}{l}\text { Atmospheric } \\
\text { lifetime }^{4} \text { (years) }\end{array}$ & $\begin{array}{l}\text { Increased } \\
\text { radiative } \\
\text { forcing } 5 \\
\left(\mathrm{~W} / \mathrm{m}^{2}\right)\end{array}$ \\
\hline \multicolumn{6}{|c|}{ Concentrations in parts per million (ppm) } \\
\hline Carbon dioxide $\left(\mathrm{CO}_{2}\right)$ & $278^{6}$ & $397.2^{7}$ & 1 & $\sim 100-300^{4}$ & 1.91 \\
\hline \multicolumn{6}{|c|}{ Concentrations in parts per billion (ppb) } \\
\hline Methane $\left(\mathrm{CH}_{4}\right)$ & $722^{8}$ & $1823^{2}$ & 28 & $12^{4}$ & 0.50 \\
\hline Nitrous oxide $\left(\mathrm{N}_{2} \mathrm{O}\right)$ & $270^{9}$ & $327^{2}$ & 265 & $121^{4}$ & 0.19 \\
\hline Tropospheric ozone $\left(\mathrm{O}_{3}\right)$ & $237^{1}$ & $337^{2}$ & n.a. ${ }^{3}$ & hours-days & 0.40 \\
\hline
\end{tabular}

Source: DoE http://cdiac.esd.ornl.gov/and IPCC Chapter 8

$\mathrm{CH}_{4}$ is removed from the atmosphere by a single process, oxidation by the hydroxyl radical $(\mathrm{OH})$, but the effect of an increase in atmospheric concentration of $\mathrm{CH}_{4}$ is to reduce the $\mathrm{OH}$ concentration, which, in turn, reduces destruction of additional methane, effectively lengthening its atmospheric lifetime. 


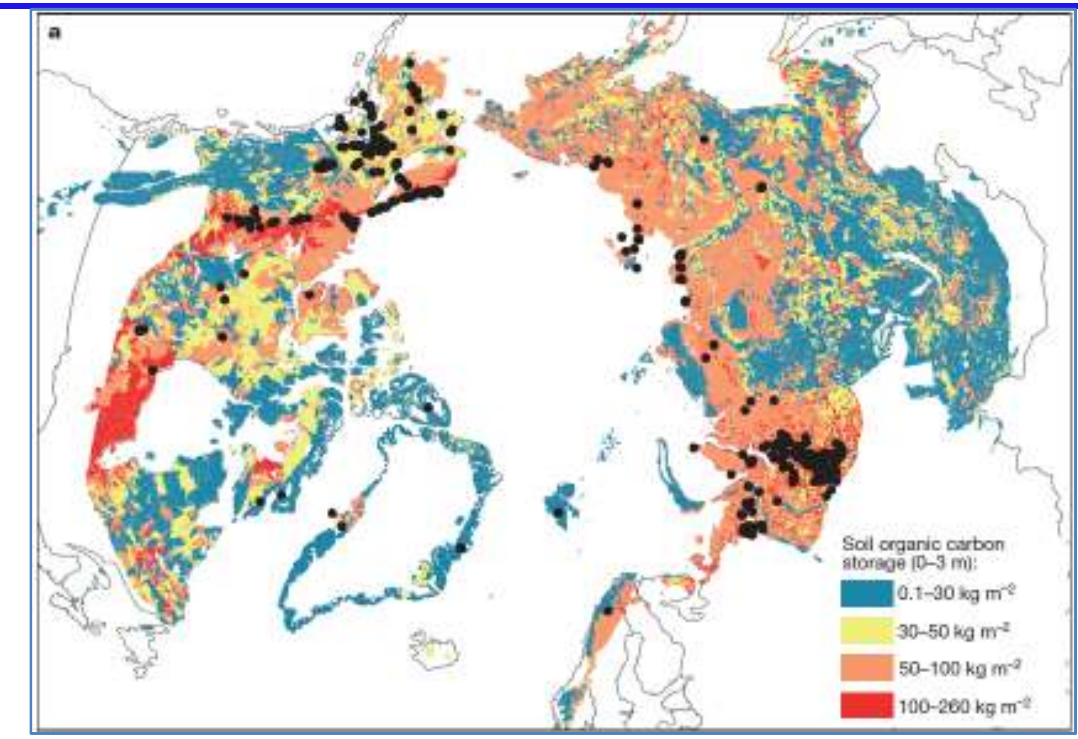

Soil organic carbon maps. a, Soil organic carbon pool $\left(\mathrm{kg} \mathrm{cm}^{2}\right)$ contained in the $0-3 \mathrm{~m}$ depth interval of the northern permafrost zone

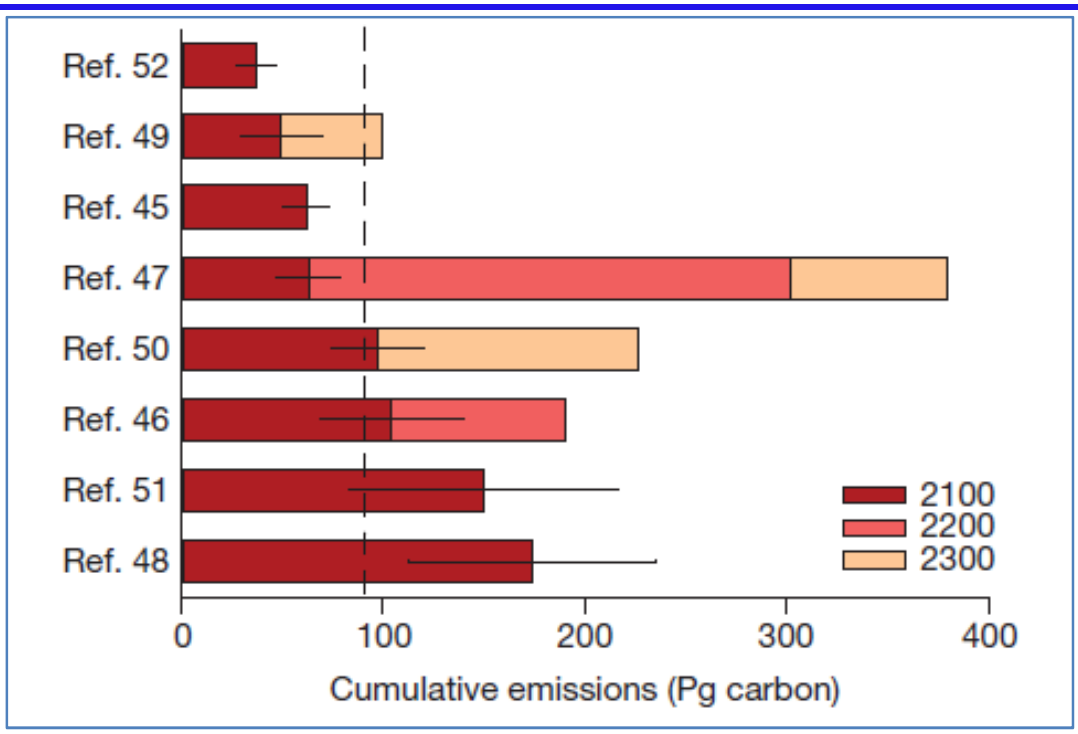

Model estimates of potential cumulative carbon release from thawing permafrost by 2100,2200 , and 2300 .

Source: E. A. G. Schuur, et.al., NATURE, VO L5 20,9APRIL 2015,174

- "Large quantities of organic carbon are stored in frozen soils (permafrost) within Arctic and sub-Arctic regions. A warming climate can induce environmental changes that accelerate the microbial breakdown of organic carbon and the release of the greenhouse gases carbon dioxide and methane. This feedback can accelerate climate change, but the magnitude and timing of greenhouse gas emission from these regions and their impact on climate change remain uncertain..." E. A. G. Schuur, et.al., NATURE, VOL 520,9 A PRIL 2015,174

- "Here, we report year-round $\mathrm{CH}_{4}$ emissions from Alaskan Arctic tundra eddy flux sites and regional fluxes derived from aircraft data. We find that emissions during the cold season (September to May) account for $\geq 50 \%$ of the annual $\mathrm{CH}_{4}$ flux, with the highest emissions from noninundated upland tundra." Donatella Zonaa et.al., "Cold season emissions dominate the Arctic tundra methane budget". PNAS, January 5, 2016 , vol. 113 , no. 1, 40-45 


\section{Measurement approach}

- Why use a laser?
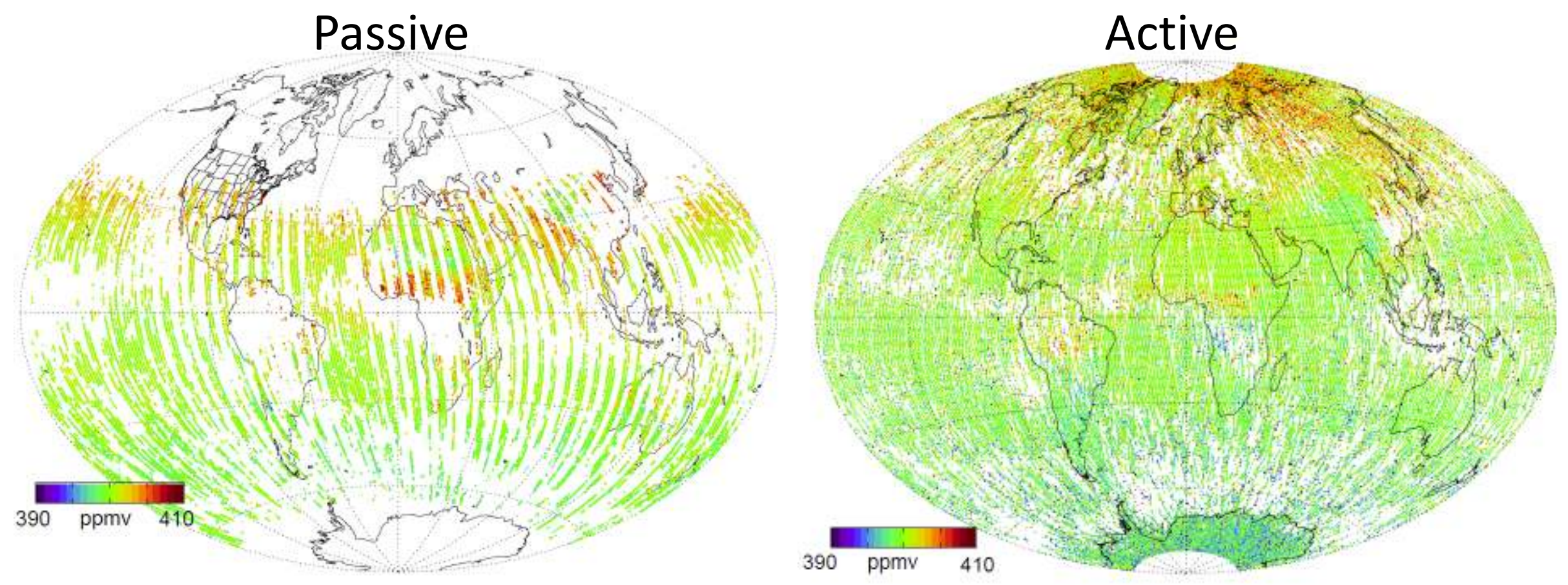

Comparison of actual OCO-2 coverage (left) vs. simulated ASCENDS coverage for December 16-31 2015. The sparse sampling OCO-2 coverage at high latitudes is a major drawback of passive remote sensing missions. (Simulation provided by Dr. Stephan R. Kawa, 614). 


\section{$\mathrm{CH}_{4}$ IPDA Lidar}

- $\quad$ Transmitter (Laser) technology

$>$ Current (optimum) Wavelength for $\mathrm{CH}_{4}$ Earth Detection: 1.64-1.66 $\mu \mathrm{m}$

$>$ Optical Parametric Oscillators (OPO) and Optical Parametric Amplifiers (OPA) are the "baseline" solutions for the transmitter.

$>$ Other options (Er:YAG and Er:YGG) now feasible.

- $\quad \underline{\text { Receiver (Detector) Technology }}$

$>$ DRS e-APD
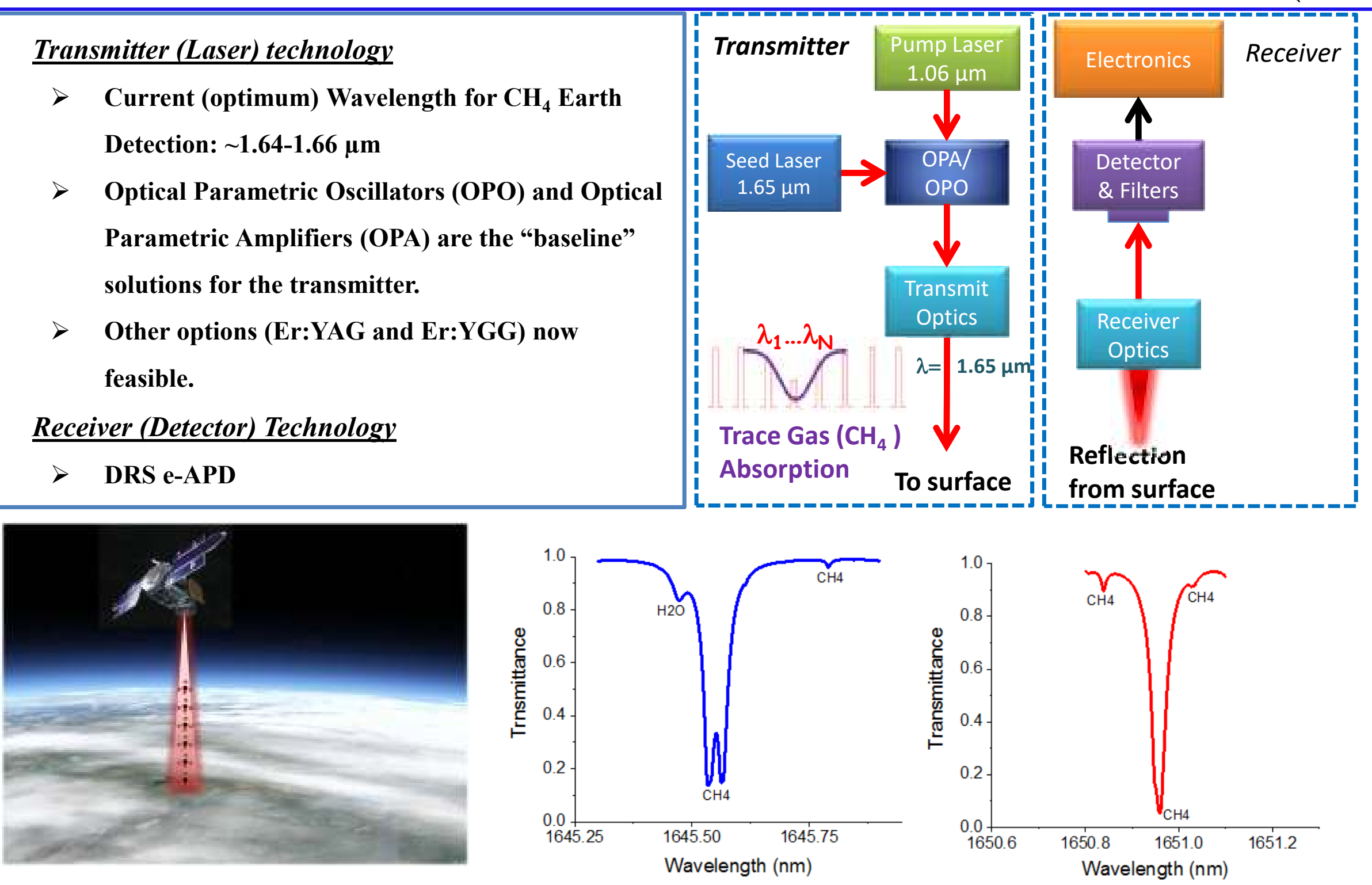
GSFC $\mathrm{CH}_{4}$ Integrated Path Differential Absorption (IPDA) Multi-Wavelength Lidar

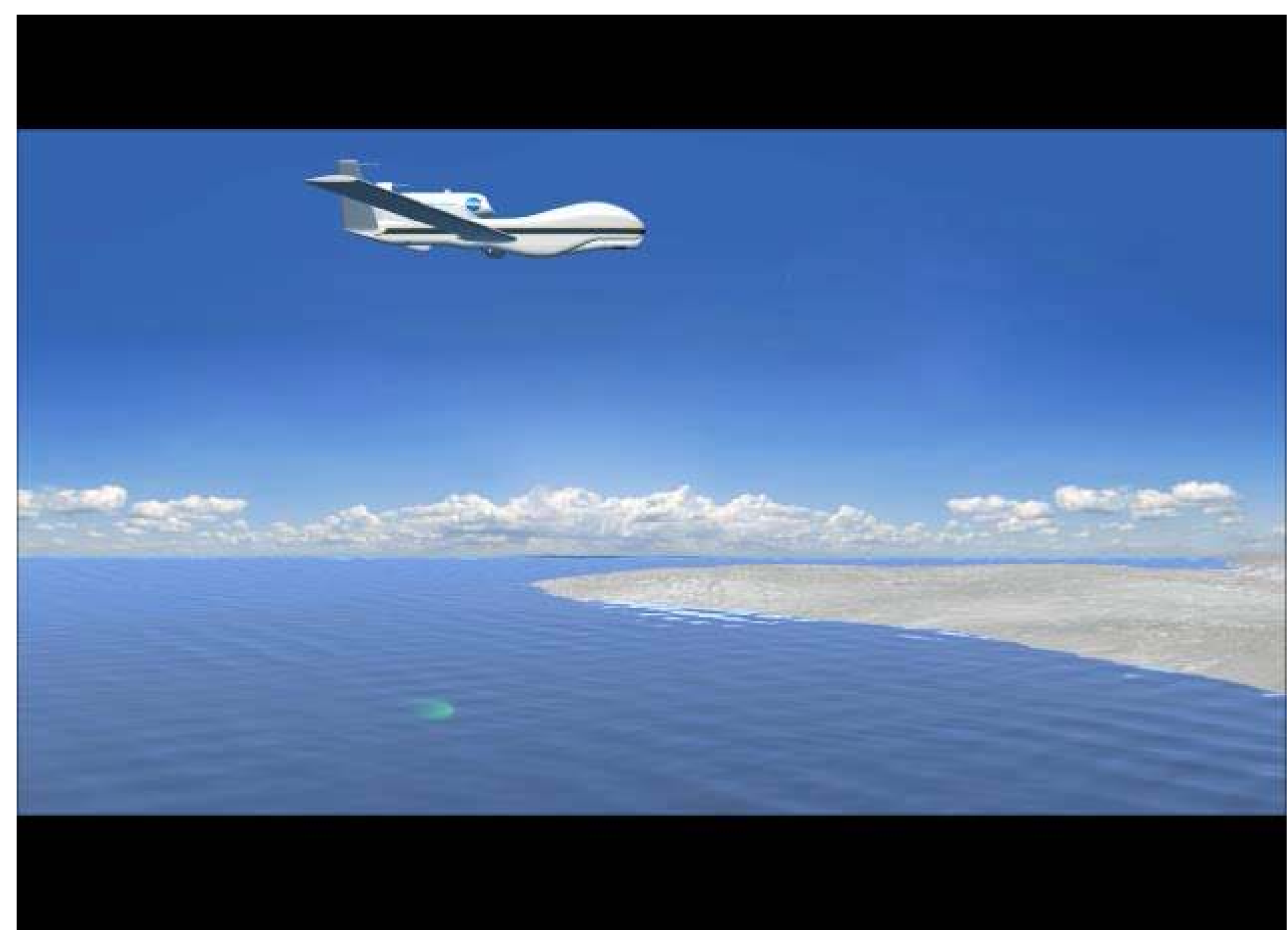




\section{Why use multiple wavelengths?}

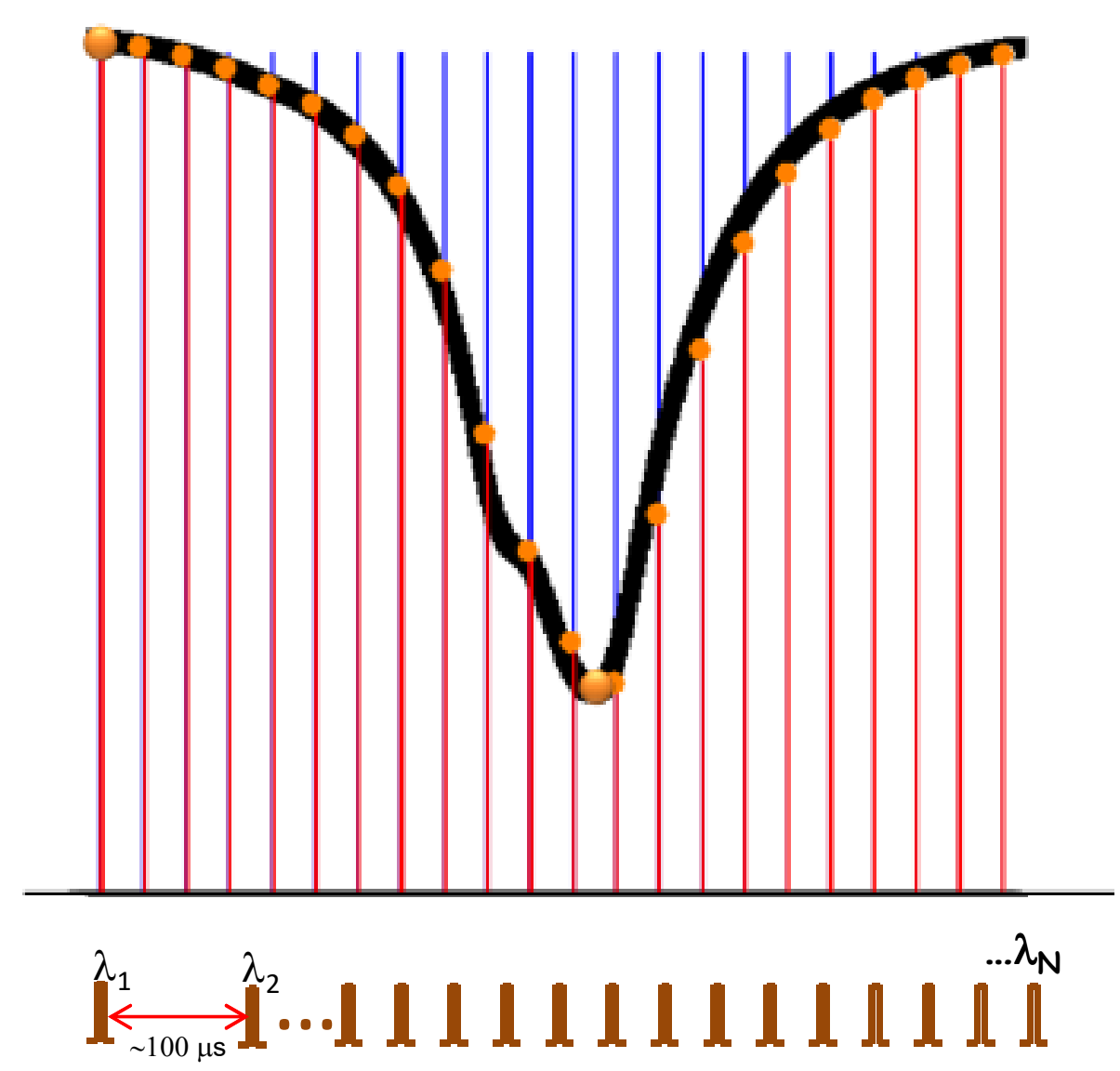

"Ideal" Instrument - has only random noise which can be averaged indefinitely.

Two wavelengths can adequately sample the lineshape. Averaging always helps.

Real Instrument - has random and non-random noise which can NOT always be averaged.

Two wavelengths can NOT adequately sample the lineshape or reduce biases. 


\section{Current GSFC Power scaling options}

\begin{tabular}{|c|c|c|c|}
\hline Approach & $\begin{array}{l}\text { \#1. OPA with smaller burst } \\
\text { pulses }\end{array}$ & $\begin{array}{l}\text { \#2. OPA with large pump } \\
\text { pulse }\end{array}$ & $\begin{array}{l}\text { \#3. OPO with large } \\
\text { pump pulse }\end{array}$ \\
\hline Pump laser & $\begin{array}{l}\text { 1. Burst mode laser. } \\
\text { Need to achieve } \\
\text { higher energy and } \\
\text { pulse uniformity. } \\
\text { Hybrid shown to work. } \\
\text { 2. Burst mode fiber } \\
\text { MOPA with } \\
\text { Waveguide Amplifier } \\
\text { shows promise }\end{array}$ & $\begin{array}{l}\text { 1. High power } \mathrm{Yb} \text { fiber } \\
\text { laser }(1030 \mathrm{~nm}) \text {. } \\
\text { 2. Planar Wave } \\
\text { Amplifier with } \\
\text { commercial laser as } \\
\text { Master Oscillator. } \\
\text { 3. Custom Nd:YAG laser }\end{array}$ & $\begin{array}{l}\text { 1. Custom Nd:YAG } \\
\text { laser (1064 } \mathrm{nm}) \\
\text { 2. High power } \mathrm{Yb} \\
\text { fiber laser ( } 1030 \\
\mathrm{~nm} \text { ). }\end{array}$ \\
\hline Seed laser & $\begin{array}{c}\text { Existing DFB lasers are OK } \\
\text { but would prefer a DBR } \\
\text { laser and higher power }\end{array}$ & $\begin{array}{l}\text { High seed power needed } \\
\text { Would prefer a DBR }\end{array}$ & $\begin{array}{l}\text { Existing DFB laser is OK } \\
\text { would prefer a DBR } \\
\text { laser and higher power }\end{array}$ \\
\hline Parametric stage & $\begin{array}{c}\text { Single OPA stage possible } \\
\text { but currently at low } \\
\text { energy. }\end{array}$ & $\begin{array}{c}\text { Need multiple OPA } \\
\text { stages to achieve high } \\
\text { power }\end{array}$ & $\begin{array}{l}\text { Need for cavity locking } \\
\text { \& step tuning }\end{array}$ \\
\hline
\end{tabular}




\section{CH4 Transmitter Technology - OPA}

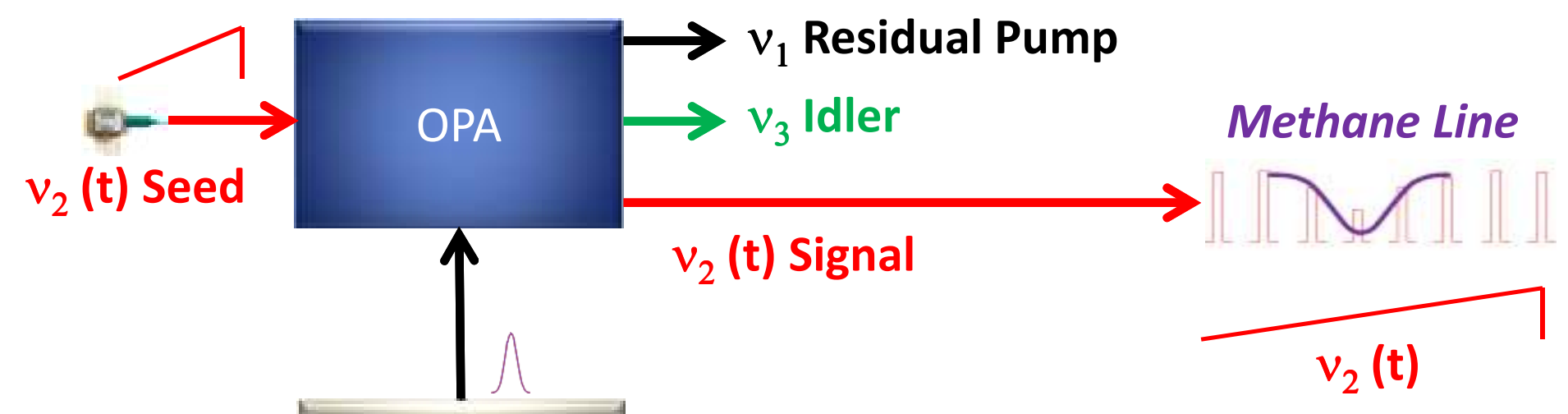

OPA: Easy to align, easy to tune, power scaling hard

$v_{1}$ Pump to achieve while maintaining narrow linewidth. OPA samples the $\mathrm{CH}_{4}$ line at several wavelengths using a single, continuously tuned seed laser 


\section{CH4 Transmitter Technology - OPO}

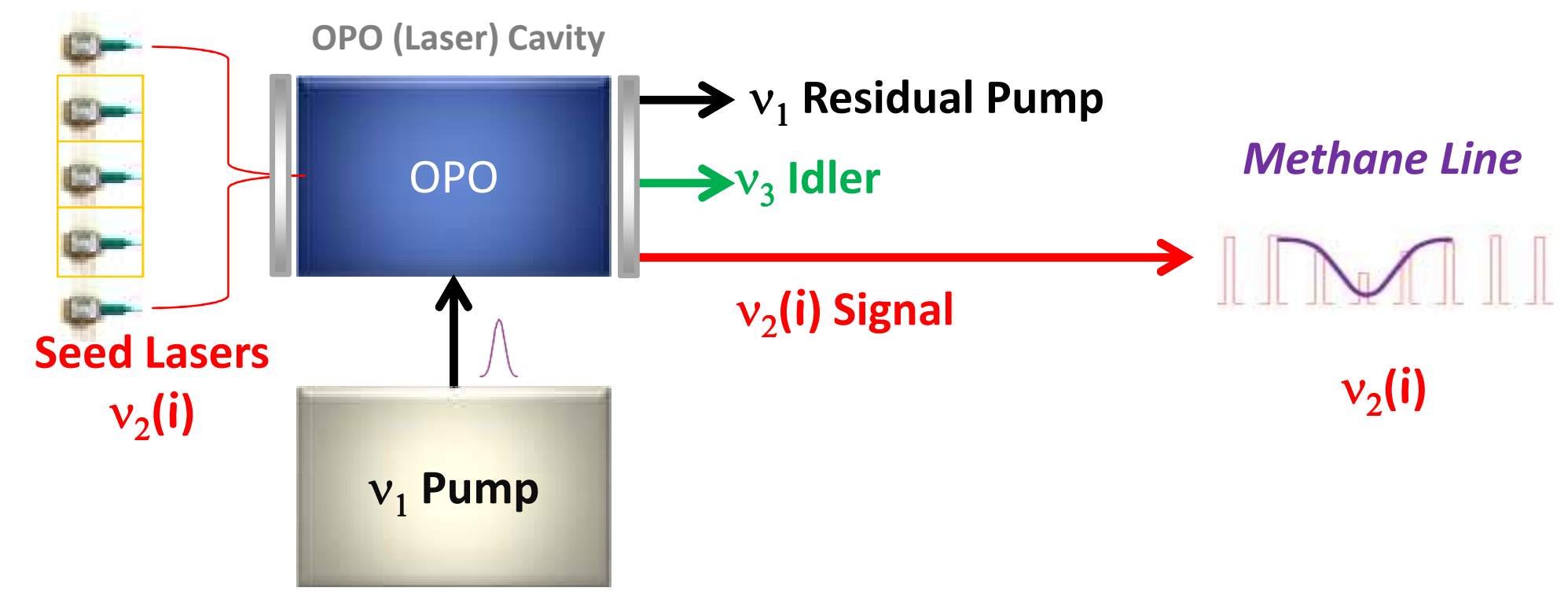

OPO: Complicated to align and tune; power scaling easier to achieve while maintaining narrow linewidth. OPO samples the $\mathrm{CH}_{4}$ line at several discrete wavelengths. All lasers must be locked. 


\section{2015 Airborne Demonstration}

Flight Demonstration on DC-8

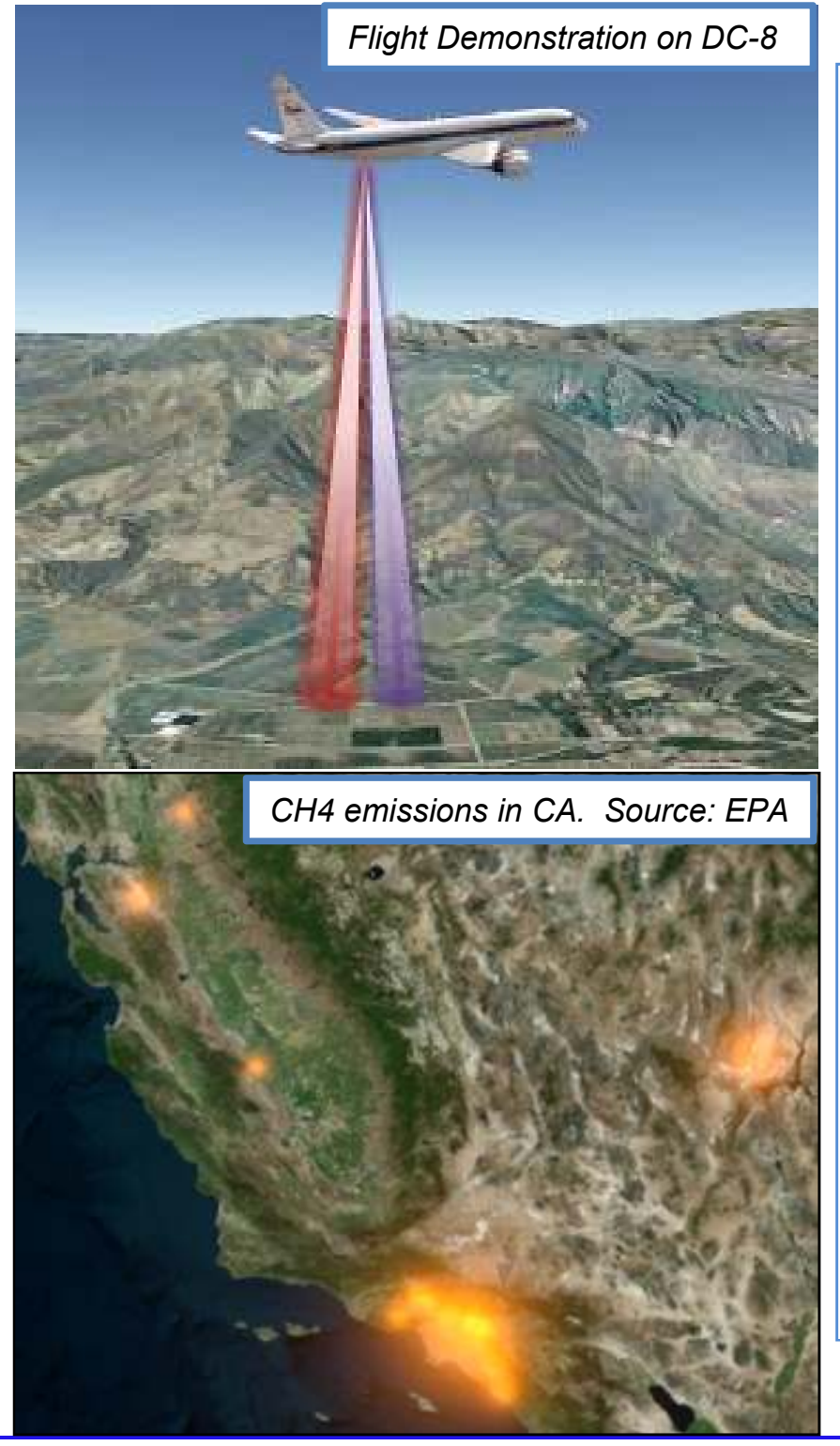

- Flight Test Methane LIDAR Instruments:

- GSFC Methane Sounder (20- $\lambda$ OPA and 5- $\lambda$ OPO)

- GSFC Picarro

- COSS-HSC Optec Solutions

- In-situ CO2 (LaRC G. Diskin)

- Conduct several test flights from NASA's Armstrong Science Aircraft Integration Facility (SAIF) in Palmdale, CA:

- 1 Engineering flight

- 2 science flights

- Approximately 12 hours of flight time in mostly in CA/NV

- Compare OPO-OPA performance

- Assess detector performance

- Assess $\mathrm{CH}_{4}$ LIDAR measurements over Western US

- Evaluate derivation of $\mathrm{XCH}_{4}$ from LIDAR observations and compare with in-situ and calibrations sites whenever possible. 


\section{$\mathrm{CH}_{4}$ Airborne Instrument}

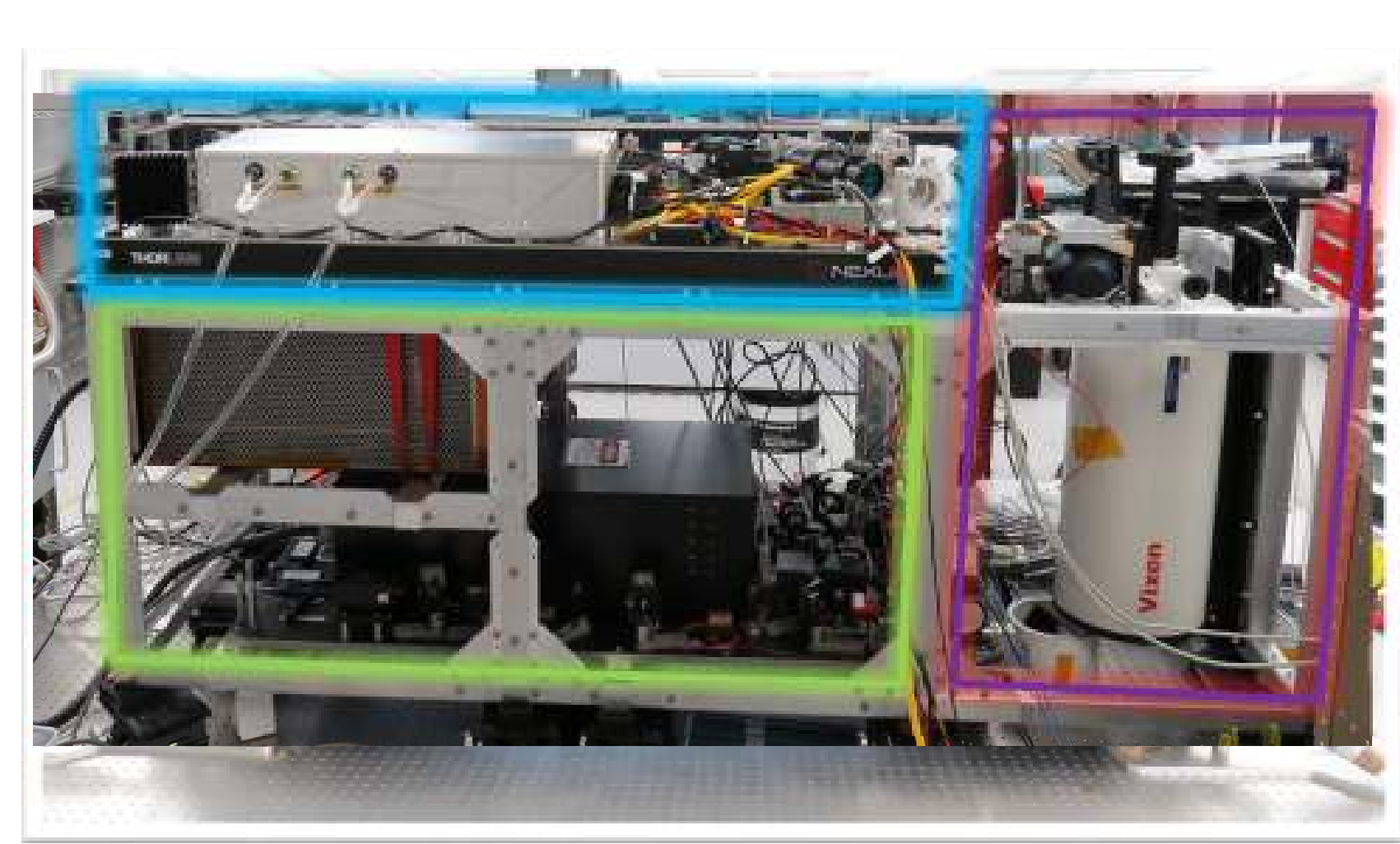

\begin{tabular}{|l|l|}
\hline Parameter & Value (OPA/OPO) \\
\hline Center $\lambda$ & $1650.9 \mathrm{~nm}$ \\
\hline Number of $\lambda$ & $20 / 5$ \\
\hline Pulse Width & $\sim 700 / 80 \mathrm{~ns}$ \\
\hline Energy/pulse & $\sim 30 / 250 \mu \mathrm{J}$ \\
\hline Bin width & $4 \mathrm{~ns}$ \\
\hline Divergence & $\sim 150 \mu \mathrm{rad}$ \\
\hline Receiver diam. & $20 \mathrm{~cm}$ \\
\hline Field of view & $300 \mu \mathrm{rad}$ \\
\hline Receiver BP & $0.8 \mathrm{~nm}(\mathrm{FWHM})$ \\
\hline Averaging time & $1 / 16 \mathrm{~s} *$ \\
\hline Detector Resp. & $\sim 1-1.5 \times 10^{9} \mathrm{~V} / \mathrm{W}$ \\
\hline
\end{tabular}

*Data analysis uses 1 s averages 


\section{Flight Tracks}

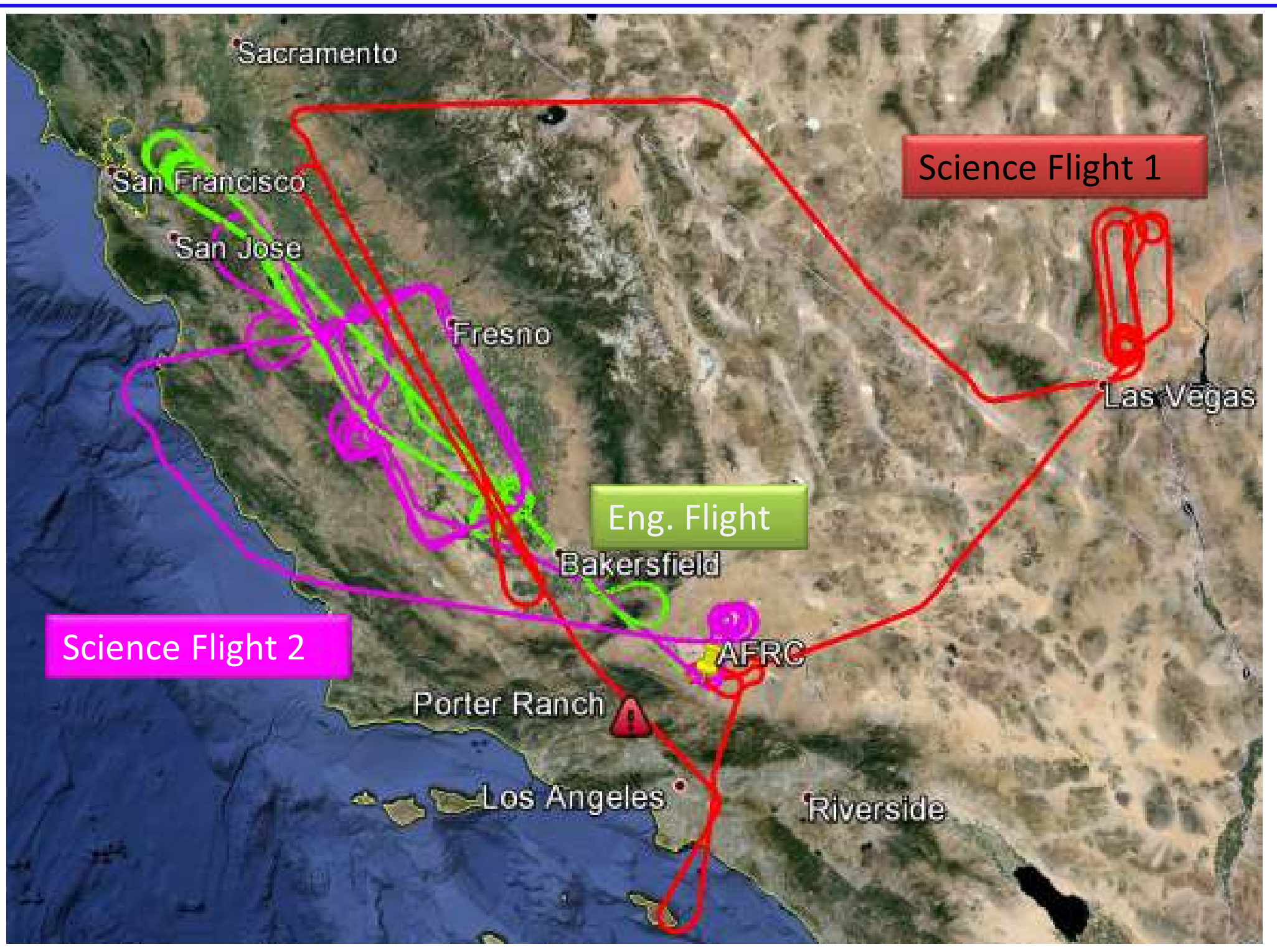




\section{Science Flight 1 (OPA)}
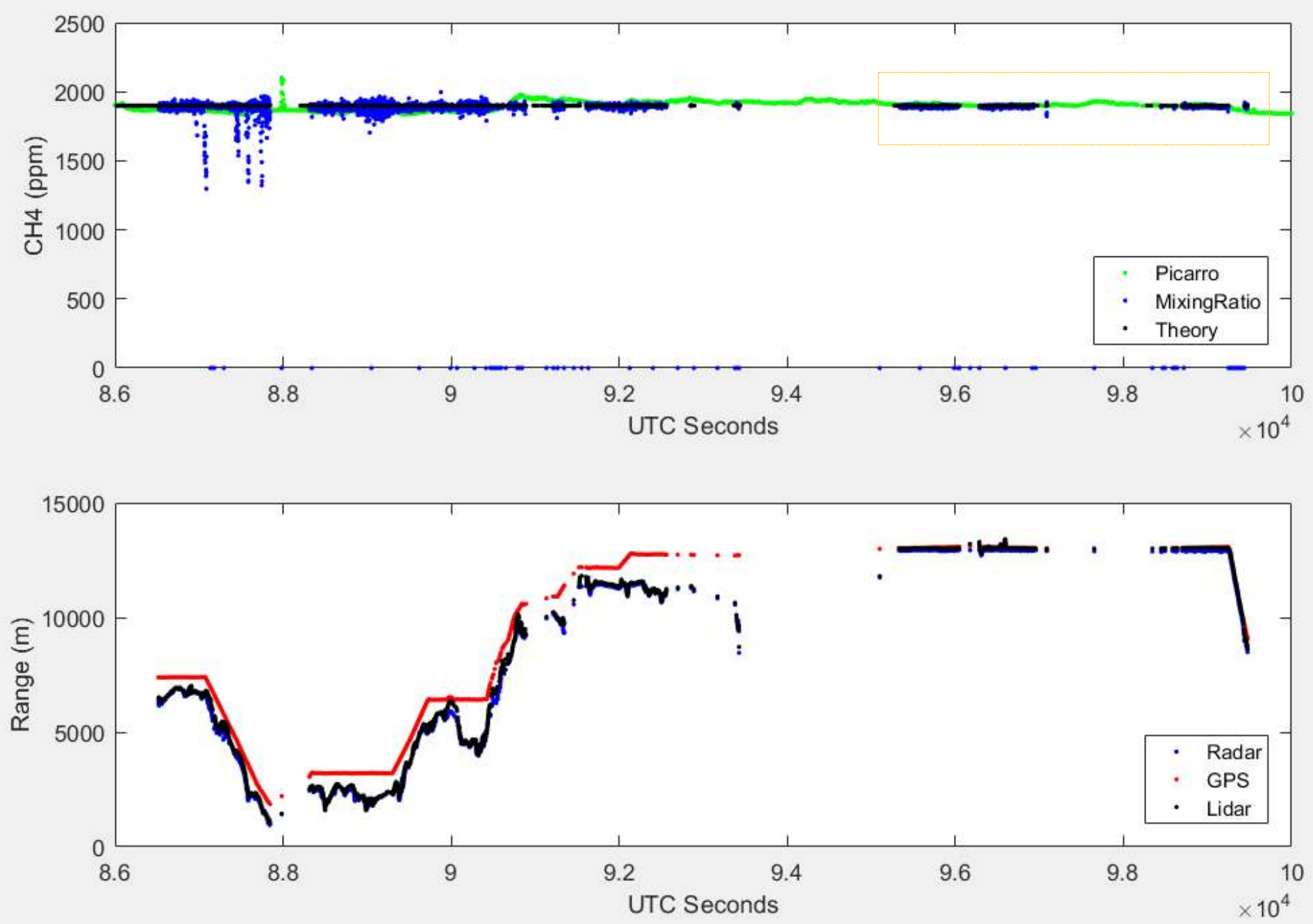


\section{Science Flight 1 (OPA)}

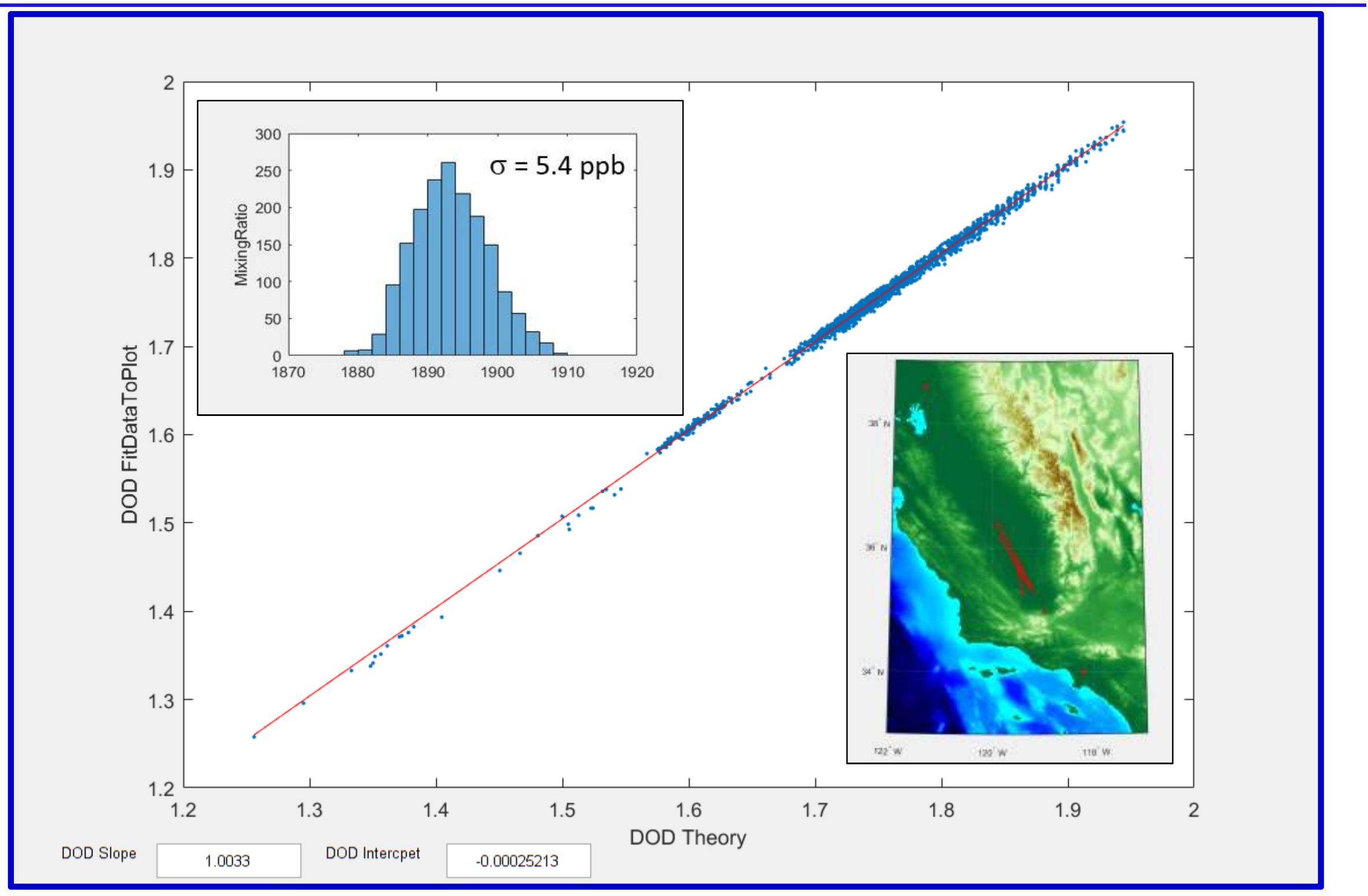




\section{Science Flight 2 (OPO)}
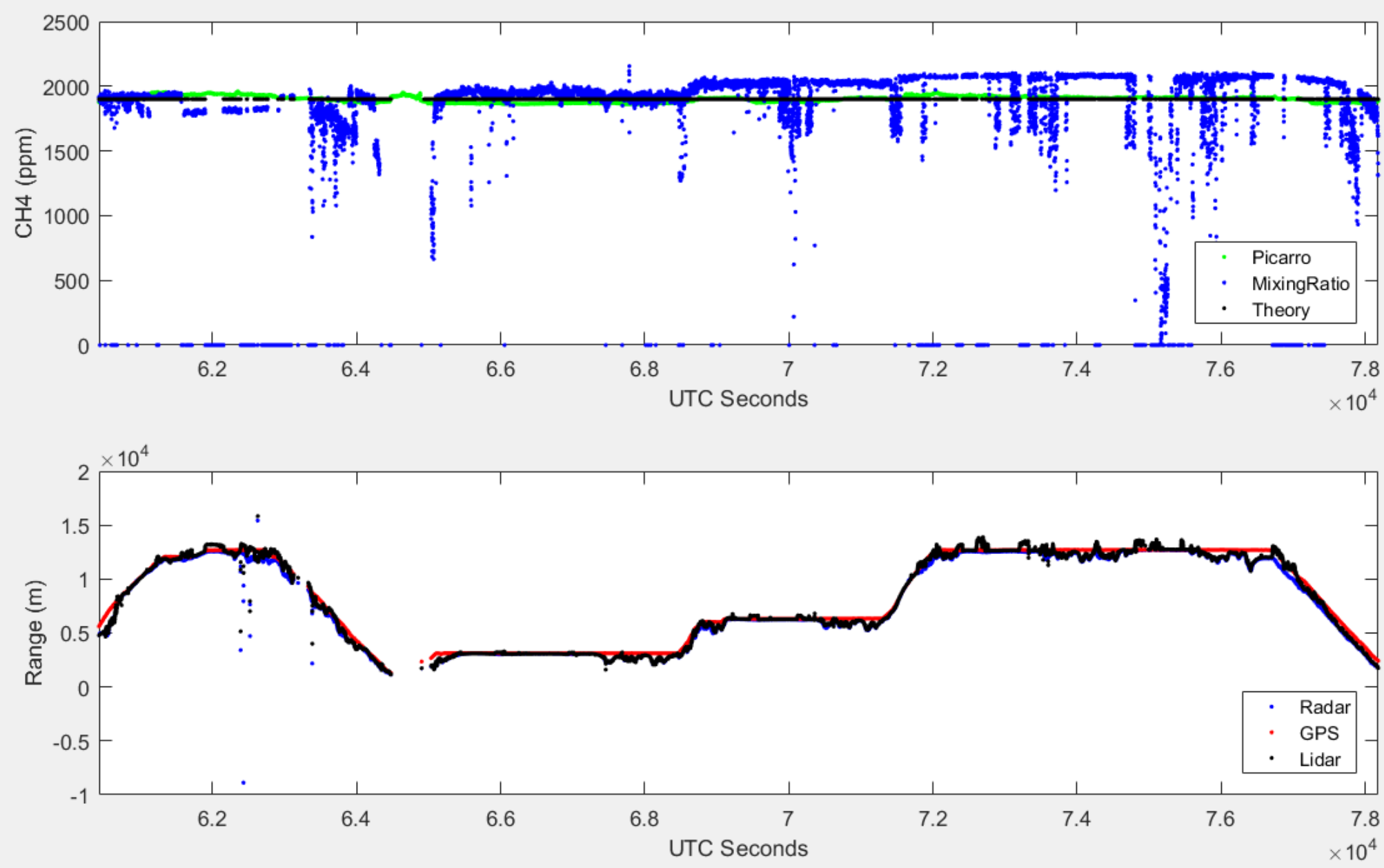


\section{Science Flight 2}

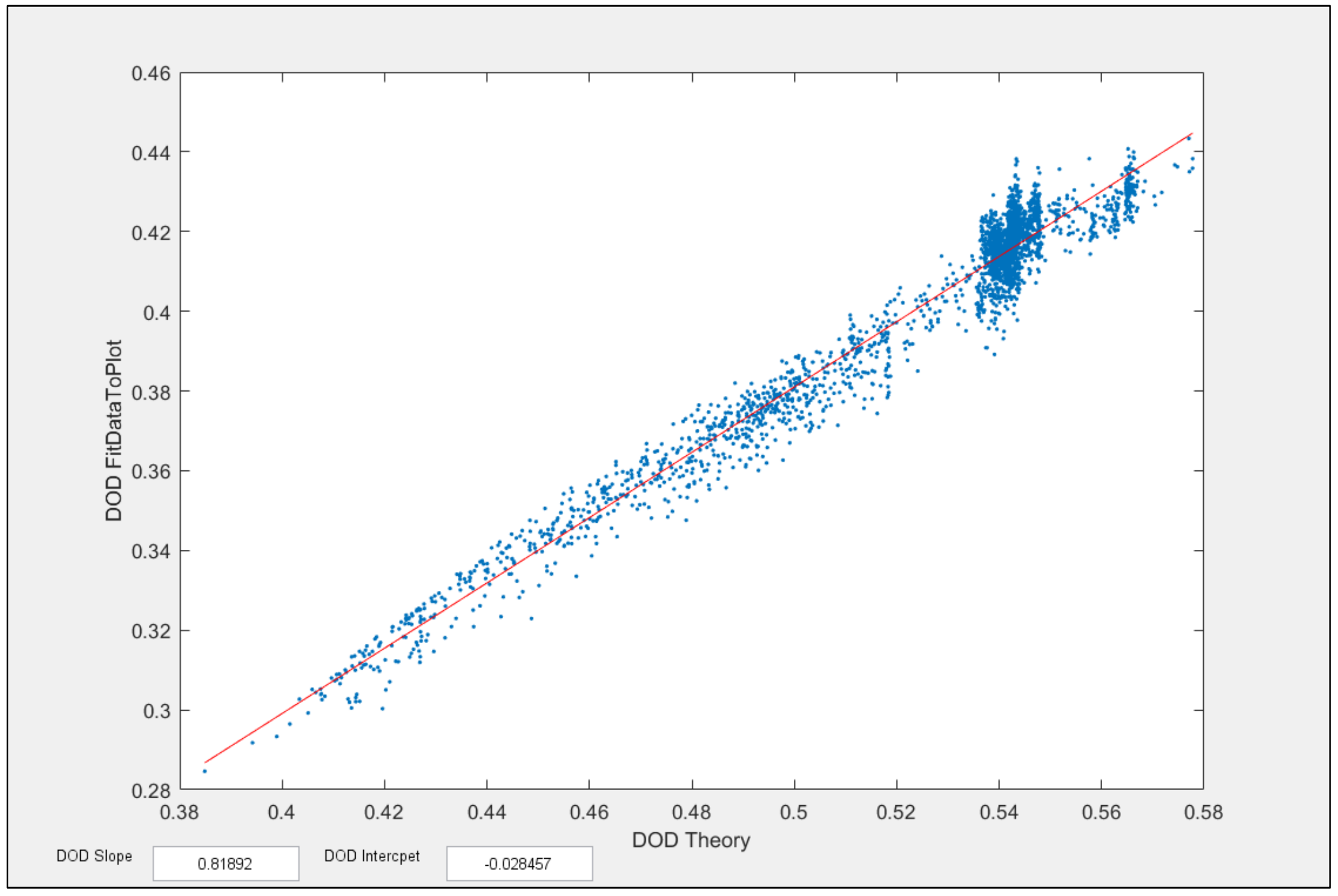




\section{Summary}

$\checkmark$ Active measurements will be a key step in obtaining measurements of $\mathrm{CH}_{4}$ with sufficient coverage, sampling, and precision to address these science questions.

$\checkmark$ Multi-wavelength IPDA lidar needed for low bias $\mathrm{CH}_{4}$ measurements.

$\checkmark$ Major technology challenges for the transmitter are being addressed.

$\checkmark$ Demonstrated $\mathrm{CH}_{4}$ airborne measurements using the two lidar transmitters (OPA and OPO). 